\title{
Predictive Risk Factors for Impaired Quality of Life in Middle- Aged Women with Urinary Incontinence
}

\author{
Youn-Jung Son, Boeun Kwon ${ }^{1}$ \\ Department of Nursing, Soonchunhyang Univeristy, Cheonan; \\ ${ }^{1}$ Department of Nursing, Seoul Women's College of Nursing, Seoul, Korea
}

\begin{abstract}
Purpose: Urinary incontinence (UI) has substantial and important impacts on quality of life (QoL). The purpose of this study was to identify the associated risk factors of QoL in middle-aged women with UI.

Methods: The participants were 127 women aged 40-64 years who experienced UI. Data were collected from October to November, 2008 using a self-reported questionnaires. The data were analyzed through t-test, one-way ANOVA, Scheffe test, and multiple linear regression with SPSS ver. 16.0 program.

Results: The distribution of UI severity was mild $18.1 \%$, moderate $40.2 \%$ and severe $41.7 \%$. In univariate analysis, differences in the score for QoL according to participants' characteristics were statistically significant on the type of delivery, number of births and severity of UI. In multiple linear regression analysis after adjustment of other variables, the most powerful predictor of QoL is severity of UI. Number of births was also significant predictor. These two variables explained 25\% of variance in QoL of women with UI.

Conclusions: UI is highly prevalent and causes suffering and impaired QoL among middle-aged women, but it stands beyond our attention. The results of this study suggest that women with moderate to severe UI should be screened for QoL by health care providers regularly. Further research is needed to determine comprehensive factors including psychosocial factors predicting the QoL for incontinent women.
\end{abstract}

Keywords: Urinary incontinence; Women; Quality of life

\section{INTRODUCTION}

Urinary Incontinence (UI) is defined by the International Continence Society as the complaint of any involuntary leakage of urine' [1]. Hunskaar et al. [2] described a prevalence pattern of 20 to $30 \%$ during young adulthood, a broad peak of prevalence around middle age (30 to $40 \%$ ).

$\mathrm{UI}$ is a more common condition in women than in men and affects women of all ages. Lee et al. [3] conducted a national survey of 13,484 women 19 years of age or older, and they found that the prevalence of UI in Korean women 19 to 29 years of age was $18.6 \%, 32.6 \%$ in ages 30 to $44,25.6 \%$ in ages 45 to 59 . Al- though UI is a common health problem that affects women physically, socially, psychologically and economically amongst women [4], there still exists a 'conspiracy of silence' [5]. Despite the availability of effective treatments, many women manage their UI silently rather than seeking professional help. Embarrassment and shame play an important role in concealing this problem. In addition, many women believe that UI is a normal consequence of childbirth and aging, thereby denying themselves treatment [6,7]. Delays in seeking help in effectively managing UI can lead to a worsening of the incontinence and in an overall decrease in quality of life (QoL) [2]. However, public exposure to this problem in recent years through commercial ad-
Corresponding author: Boeun Kwon

Department of Nursing, Seoul Women's College of Nursing,

287-89 Hongje 3-dong, Seodaemun-gu, Seoul 120-742, Korea

Tel: +82-2-2287-1736 / Fax: +82-2-395-8018 / E-mail: bekwon@snjc.ac.kr

Submitted: December 7, 2010 / Accepted after revision: December 22, 2010
This is an Open Access article distributed under the terms of the Creative Commons Attribution Non-Commercial License (http://creativecommons.org/licenses/by-nc/3.0/) which permits unrestricted non-commercial use, distribution, and reproduction in any medium, provided the original work is properly cited. 
vertisements, the internet and exhibit of many types of protective products, has facilitated greatly for women to seek health care, although the frequency is still low [8].

UI is not a life-threatening condition, but UI has a physical and psychological affect on the women's daily life, and it charges them with an additional financial burden $[9,10]$. Even though, the prevalence of UI is similar to other chronic diseases, research with regards to its effect on the QoL of the women have started only recently in the last fifteen years $[11,12]$. But much of the published literature pertaining to UI is focused on prevalence, risk factors, treatment, and cost implications $[5,13,14]$. Few studies have evaluated the relationships between UI and QoL in community dwelling women [12,15].

The aims of this community-based cross-sectional study were to investigate the associated risk factors of QoL in middle-aged women whom the presence of UI was determined by their responses to a validated questionnaire in Seoul and Gyeonggi province, a metropolitan region of South Korea.

\section{MATERIALS AND METHODS}

\section{Study Design}

This study was carried out as a cross-sectional and community based study design using a questionnaire survey.

\section{Study Population and Setting}

There were 127 community-dwelling, Korean women ages 4064 years and older who self-identified themselves as being incontinent. Participants were given the assurance that they could withdraw from the research without fear of reprisal or denial of present or future health care services. These women were invited to participate in the study.

\section{Instruments}

\section{Participant characteristics}

Socio-demographic characteristics included age, spouse status, and education. Health related factors were body mass index (BMI) and comorbidity such as coexistent chronic illness. Participants were classified as lower weight $\left(<18.5 \mathrm{~kg} / \mathrm{m}^{2}\right)$, normal weight (18.5-22.9 kg/m²), overweight (23.0-24.9 kg/m $\left.{ }^{2}\right)$, and obesity ( $\geq 25 \mathrm{~kg} / \mathrm{m}^{2}$ ) according to the guideline of the Korean Society for the Study of Obesity. Gynecological history included menopause, types of delivery, number of births, and experience of UI treatment.

\section{Self-reported UI}

All subjects were asked the question: "Over the past 12 months, how often do you have difficulty holding your urine until you can get to a toilet?" Responses included "never, hardly ever, some, most or all of the time." Subjects were considered to have urinary incontinence if they responded "some, most, or all of the time."

\section{Incontinence Severity Index}

Severity of UI was defined based on frequency and amount of leakage using the Incontinence Severity Index. This index, originally developed in the Research Council of Norway, provided a simple severity index of female incontinence and had been previously used in community based, epidemiological survey research [16].

The severity index was calculated based on frequency and amount of leakage. It was composed of two questions. The first question assessed frequency of UI and offered four levels of responses (1, once or less/month; 2 , few times/month; 3 , few times/week; 4 , every day). The second question assessed the amount of UI and offered two levels of responses (1, only drops or a little; 2 , more than a little). Descriptively, slight incontinence denoted drops of leakage a few times a month, moderate incontinence denoted daily drops of leakage, and severe incontinence denoted larger amounts of urinary leakage at least once a week. Previous research using the Incontinence Severity Index has reported solid levels of validity, responsiveness, and reliability [2].

\section{Quality of life}

The UI condition-specific QoL measure, developed by Kim and Lee [17], was used in this study. This QoL questionnaire has 12 items and provides a 4-point Likert scale for responses. Response options range from ' 1 ' indicating 'extremely' to ' 4 ' indicating 'not at all. The Cronbach's alpha of QoL was 0.87.

\section{Data Collection and Procedure}

Data for this study were collected using a questionnaire form prepared by the researchers on the information in participant recruitment was conducted in 8 churches and two temple located in Seoul and Gyeonggi province.

Announcements in weekly church and temple bulletins were used as a recruitment strategy. After obtaining the permission of the appropriate pastors and chief monk, the trained research assistants attended a Sunday service in all study sites and placed 
announcements in the bulletins. Inclusion criteria included that women were aged 40-64 years old, and self-identified as being incontinent. When inclusion criteria had been verified, the researcher assistants provided the potential participant with a study disclaimer. If reading comprehension was a concern, this disclaimer was verbally provided. Once study participation was obtained from subjects, the questionnaires were provided to the participant. These completed at the churches and temples.

\section{Data Analysis}

All data were entered in the SPSS ver. 16.0 (SPSS Inc., Chicago, IL, USA), which was then utilized for data analyses. Descriptive statistics were used to describe the study population and determine characteristics and QoL scores. For the purposes of this study, independent t-test, one way ANOVA, Scheffe test and multiple linear regression with stepwise method were used. Statistical significance was set at the $5 \%$ level $(\mathrm{P}<0.05)$.

\section{RESULTS}

The ages of women who participated in the study ranged from 40 to 64 years, mean 48.77 (standard deviation [SD], 7.39). As shown in Table 1, presence of their spouse was one hundred and seventeen (92.1\%). Seventy-six (59.8\%) had a post-high school education. The mean of BMI was 22.72 (SD, 2.42). Vaginal delivery (77.2\%) was more than cesarian section $(22.8 \%)$ in types of delivery and $79.5 \%$ of participants had 2 or 3 number of births. In severity of UI, more than half of all participants were moderate or severe form. Only $27.6 \%$ of the middle-aged women with UI had sought medical treatment. The mean of QoL was 44.24 (SD, 3.49), with a range of 4 to 48.

Mean differences in total scores of QoL, according to the participants' characteristics were presented in Table 2. Types of delivery ( $t,-2.22 ; \mathrm{P}=0.033)$, number of births ( $\mathrm{F}, 3.37 ; \mathrm{P}=0.038$ ), and severity of UI (F, 18.39; $\mathrm{P}<0.001)$ were statistical significant variables. No association was found between age, spouse, education, menopause, BMI, types of delivery, comorbidity and experience of UI treatment.

In Table 3, linear multiple regression analysis with stepwise method was conducted to determine the predominant predictors of QoL in middle-aged women with UI. Severity of UI ( $\beta$, -0.443 ; $\mathrm{P}<0.001)$ was negatively associated with $\mathrm{QoL}$, but numer of births $(\beta, 0.263 ; \mathrm{P}=0.001)$ was positively associated with OoL. These variables explained $25 \%$ (adjusted $\mathrm{R}^{2}, 0.248$ ) of the variance for QoL in the middle-aged women in UI.
Table 1. The general characteristics and quality of life in middle-aged women with UI $(\mathrm{n}=127)$

\begin{tabular}{|c|c|c|c|}
\hline Characteristics & Category & No. (\%) & Mean \pm SD \\
\hline \multirow[t]{3}{*}{ Age (yr) } & $40-49$ & $46(36.2)$ & $48.77 \pm 7.39$ \\
\hline & $50-59$ & $63(49.6)$ & \\
\hline & $60-64$ & $18(14.2)$ & \\
\hline \multirow[t]{2}{*}{ Spouse } & No & $10(7.9)$ & \\
\hline & Yes & $117(92.1)$ & \\
\hline \multirow[t]{3}{*}{ Education } & $\begin{array}{l}\text { Below elementary } \\
\text { school }\end{array}$ & $13(10.2)$ & \\
\hline & Middle school & $38(29.9)$ & \\
\hline & Above high school & $76(59.8)$ & \\
\hline \multirow[t]{2}{*}{ Menopause } & No & $67(52.8)$ & \\
\hline & Yes & $60(47.2)$ & \\
\hline \multirow{4}{*}{$\begin{array}{l}\text { Body mass index } \\
\left(\mathrm{kg} / \mathrm{m}^{2}\right)\end{array}$} & Low $(<18.5)$ & $9(7.1)$ & $22.72 \pm 2.42$ \\
\hline & Normal (18.5-22.9) & $60(47.2)$ & \\
\hline & $\begin{array}{c}\text { Over weight } \\
(23.0-24.9)\end{array}$ & $35(27.6)$ & \\
\hline & Obese $(\geq 25)$ & $23(18.1)$ & \\
\hline \multirow[t]{2}{*}{ Types of delivery } & Cesarian section & $29(22.8)$ & \\
\hline & Vaginal & $98(77.2)$ & \\
\hline \multirow[t]{3}{*}{ Number of births } & 1 & $16(12.6)$ & \\
\hline & $2-3$ & $101(79.5)$ & \\
\hline & $\geq 4$ & $10(7.9)$ & \\
\hline \multirow[t]{2}{*}{ Comorbidity } & No & $88(69.3)$ & \\
\hline & Yes & $39(30.7)$ & \\
\hline \multirow[t]{3}{*}{ Severity of UI } & Mild & $23(18.1)$ & \\
\hline & Moderate & $51(40.2)$ & \\
\hline & Severe & $53(41.7)$ & \\
\hline \multirow{2}{*}{$\begin{array}{l}\text { Experience of UI } \\
\text { treatment }\end{array}$} & No & $92(72.4)$ & \\
\hline & Yes & $35(27.6)$ & \\
\hline Quality of life & & & $44.24 \pm 3.49$ \\
\hline
\end{tabular}

UI, urinary incontinence.

\section{DISCUSSION}

Although there are multiple factors of UI that have the potential to affect QoL, an increased severity of incontinence has been identified as a predictor of impact on QoL with UI by a number of studies [18-20].

There is a consistent misunderstanding that $\mathrm{UI}$ in female is a normal consequence of aging. While normal aging is not a cause of incontinence, age-related change in lower urinary tract func- 
tion predispose the older person to UI. In this study of middleaged women recruited from community, UI severity was associated with QoL, as the severity of UI in women increased, the

Table 2. Differences of quality of life according to the general characteristics in middle aged women with UI $(n=127)$

\begin{tabular}{|c|c|c|c|}
\hline Characteristics & Category (n) & Mean \pm SD & t or $F(P)$ \\
\hline \multirow{3}{*}{ Age (yr) } & $40-49(46)$ & $44.33 \pm 3.57$ & $1.02(0.366)$ \\
\hline & $50-59(63)$ & $43.91 \pm 3.68$ & \\
\hline & $60-64(18)$ & $45.22 \pm 2.39$ & \\
\hline \multirow[t]{2}{*}{ Spouse } & No (10) & $43.30 \pm 6.23$ & $-0.51(0.619)$ \\
\hline & Yes (117) & $44.32 \pm 3.19$ & \\
\hline \multirow[t]{3}{*}{ Education } & $\begin{array}{l}\text { Below elementary } \\
\text { school (13) }\end{array}$ & $44.69 \pm 2.78$ & $0.51(0.601)$ \\
\hline & Middle school (38) & $44.60 \pm 2.83$ & \\
\hline & $\begin{array}{l}\text { Above high school } \\
\text { (76) }\end{array}$ & $43.98 \pm 3.89$ & \\
\hline \multirow[t]{2}{*}{ Menopause } & No (67) & $43.92 \pm 4.02$ & $-1.12(0.270)$ \\
\hline & Yes (60) & $44.60 \pm 2.78$ & \\
\hline \multirow{4}{*}{$\begin{array}{l}\text { Body mass } \\
\text { index }\left(\mathrm{kg} / \mathrm{m}^{2}\right)\end{array}$} & Low (9) & $42.89 \pm 3.85$ & $1.89(0.134)$ \\
\hline & Normal (60) & $45.56 \pm 4.05$ & \\
\hline & Over weight (35) & $44.43 \pm 3.00$ & \\
\hline & Obese (23) & $43.83 \pm 1.82$ & \\
\hline \multirow[t]{2}{*}{ Types of delivery } & $\begin{array}{l}\text { Cesarian section } \\
(29)\end{array}$ & $42.62 \pm 4.85$ & $-2.22(0.033)$ \\
\hline & Vaginal (98) & $44.72 \pm 2.83$ & \\
\hline \multirow[t]{3}{*}{ No. of births } & $1^{\text {a) }}(16)$ & $42.25 \pm 5.36$ & $3.37(0.038)$ \\
\hline & $2-3^{\mathrm{b})}(101)$ & $44.45 \pm 3.18$ & a) $<$ b),c) \\
\hline & $\geq 4^{\text {c) }}(10)$ & $45.30 \pm 1.34$ & \\
\hline \multirow[t]{2}{*}{ Comorbidity } & No (88) & $44.43 \pm 3.33$ & $0.91(0.365)$ \\
\hline & Yes (39) & $43.82 \pm 3.85$ & \\
\hline \multirow[t]{3}{*}{ Severity of UI } & $\operatorname{Mild}^{\mathrm{a})}(23)$ & $45.91 \pm 1.80$ & $18.39(<0.001)$ \\
\hline & Moderate $^{\mathrm{b})}(51)$ & $45.53 \pm 2.39$ & a),b) $>$ c) \\
\hline & Severe $^{\text {c) }}(53)$ & $42.28 \pm 3.99$ & \\
\hline \multirow{2}{*}{$\begin{array}{l}\text { Experience of } \\
\text { UI Treatment }\end{array}$} & No (92) & $44.58 \pm 3.57$ & $1.75(0.083)$ \\
\hline & Yes (35) & $43.37 \pm 3.16$ & \\
\hline
\end{tabular}

ANOVA was followed by Scheffe's F-test. UI, urinary incontinence.
QoL worsen significantly after controlling for several characteristics. It is recognized that as the severity of UI increases, QoL decreases, a finding consistent with the research of Ozerdogan et al. [21] in Turkey. This result suggests that women with severe UI might go through low physical and psychological wellbeing, and that the severity of UI that tends to be lasting, and bothersome. Therefore, health care providers should be needed to a better understanding of women's experiences and improve health services including counseling and assessment for aged women with UI.

In our study, number of births also identified as an associated risk factor to QoL in women with UI. Some research findings showed that the prevalence of UI during pregnancy was very high $[7,22]$. During pregnancy most women with UI experience minimal impact on QoL. Postnatally, other causes of morbidity may contribute to worsening of general and personal health [22]. Therefore, health care providers involved in the care of pregnant women about UI plan to provide more intensive education programs directed towards the prevention of UI during pregnancy and postpartum.

On the other hand, BMI is one of the predominant risk factors in prevalence of UI [7,23-25], but it is not associated with QoL with UI women in our study. By previous studies, the lack of an association of BMI with clinically significant UI implies that this factor might not affect a woman's daily life $[2,5,6]$. In spite of our insignificant results, a higher BMI is still discouraged as obesity is related to higher abdominal pressures and can cause mild UI. Future study should be needed to identify relationships between BMI and QoL.

According to the findings of Kim et al. [15], Only 10.4\% of women with UI replied for seeking medical treatment and 64.6\% of women with UI regarded incontinence as a confidential to others even without any medical treatments and help. These findings were similarly shown in our research. It might be explained most women with UI tends to regard incontinence is not serious medical condition because UI is not considered lifethreatening and does not show any uncomfortable and serious signs and symptoms such as pain or bleeding even though UI

Table 3. Predictors of quality of life in middle-aged women with UI $(n=127)$

\begin{tabular}{lcccccccc}
\hline Predictors & Standardized $\beta$ & $\mathrm{t}$ & $\mathrm{P}$-value & $\mathrm{R}^{2}$ Change & $\mathrm{R}^{2}$ & Adjusted $\mathrm{R}^{2}$ & $\mathrm{~F}$ & $\mathrm{P}$-value \\
\hline Severity of UI & -0.443 & -5.730 & $<0.001$ & 0.191 & 0.260 & 0.248 & 21.806 & $<0.001$ \\
No. of births & 0.263 & 3.407 & 0.001 & 0.069 & & & &
\end{tabular}

UI, urinary incontinence. 
has been shown negative effects on women's wellbeing $[13,18]$. On the other hand, Vinker et al. [26], showed that the greater the subjective disturbance caused by UI, the greater the likelihood of patients seeking medical advice and treatment. So health care professionals have to understand a gap between subjective perception and severity of UI symptoms of aged women.

Limitations of this study that may have threatened the validity of these results are related to methodological issues. First, the data collection methods used may be associated with response error. Data were collected using either self-report or personal administration of the study materials. It is recognized that personal administration provides a more optimistic picture of health than self-report. Second, we did not have information on types of incontinence, thus, we could not explore whether risk factors vary for stress, urge, or mixed types of UI. Despite of these limitations, the present findings demonstrated that severity of UI and number of births presented a significant impact in community-dwelling, middle-aged women's QoL. These results emphasize the need of healthcare professionals to address this problem. Furthermore, primary and secondary healthcare services should organize multidisciplinary teams to see UI patients, guide them and provide individualized care taking into account their emotional and psychosocial aspects.

In conclusion, our findings suggest that self perceived disease severity significantly influences QoL among middle-aged women with UI. Therefore, health care providers are needed to screen for problematic incontinence by asking if the severity of incontinence is bothersome. Also, health care providers should focus on assessment for women with UI carefully with awareness of seeking help often depends on beliefs and understanding of how the condition can be treated.

Future studies are needed to explore various risk factors including psychosocial factors such as depression for QoL and identify the effect of education program related to identification and managing UI improves QOL for women with UI.

\section{CONFLICT OF INTEREST}

No potential conflict of interest relevant to this article was reported.

\section{REFERENCES}

1. Abrams P, Cardozo L, Fall M, Griffiths D, Rosier P, Ulmsten U, et al. The standardisation of terminology of lower urinary tract func- tion: report from the standardisation sub-committee of the International Continence Society. Neurourol Urodyn 2002;21:167-78.

2. Hunskaar S, Burgio K, Clark A, Lapitan MC, Nelson R, Sillen U, et al. Epidemiology of faecal and urinary incontinence and pelvic organ prolapse. In: Abrams P, Cardozo L, Khoury S, Wein A, editors. Incontinence. Plymouth: Health Publication Ltd; 2005. p. 257-312.

3. Lee KS, Sung HH, Na S, Choo MS. Prevalence of urinary incontinence in Korean women: results of a National Health Interview Survey. World J Urol 2008;26:179-85.

4. Kocak I, Okyay P, Dundar M, Erol H, Beser E. Female urinary incontinence in the west of Turkey: prevalence, risk factors and impact on quality of life. Eur Urol 2005;48:634-41.

5. Botlero R, Bell RJ, Urquhart DM, Davis SR. Urinary incontinence is associated with lower psychological general well-being in community-dwelling women. Menopause 2010;17:332-7.

6. Charalambous S, Trantafylidis A. Impact of urinary incontinence on quality of life. Pelviperineology 2009;28:51-3.

7. Danforth KN, Townsend MK, Lifford K, Curhan GC, Resnick NM, Grodstein F. Risk factors for urinary incontinence among middleaged women. Am J Obstet Gynecol 2006;194:339-45.

8. Wallner LP, Porten S, Meenan RT, O'Keefe Rosetti MC, Calhoun EA, Sarma AV, et al. Prevalence and severity of undiagnosed urinary incontinence in women. Am J Med 2009;122:1037-42.

9. Bushnell DM, Martin ML, Summers KH, Svihra J, Lionis C, Patrick DL. Quality of life of women with urinary incontinence: cross-cultural performance of 15 language versions of the I-QOL. Qual Life Res 2005;14:1901-13.

10. Saadoun K, Ringa V, Fritel X, Varnoux N, Zins M, Breart G. Negative impact of urinary incontinence on quality of life, a cross-sectional study among women aged 49-61 years enrolled in the GAZEL cohort. Neurourol Urodyn 2006;25:696-702.

11. Cortes E, Kelleher C. Urinary incontinence and quality of life. Women's Health Med 2005;2:1-3.

12. Kang Y, Phillips LR, Kim SS. Incontinence quality of life among Korean-American women. Urol Nurs 2010;30:130-6, 129.

13. Holroyd-Leduc JM, Straus SE. Management of urinary incontinence in women: scientific review. JAMA 2004;291:986-95.

14. Miller KL. Stress urinary incontinence in women: review and update on neurological control. J Womens Health (Larchmt) 2005; 14:595-608.

15. Kim HJ, Lee HS, Lee SH, Shim KW, Suh HS, Kong KA, et al. The impact of urinary incontinence on the quality of life in women. J Korean Acad Fam Med 2003;24:709-14.

16. Sandvik H, Hunskaar S, Seim A, Hermstad R, Vanvik A, Bratt H. Validation of a severity index in female urinary incontinence and 
its implementation in an epidemiological survey. J Epidemiol Community Health 1993;47:497-9.

17. Kim JS, Lee JZ. The prevalence of urinary incontinence in elderly women at institutionalized facilities in Pusan. Korean J Urol 1999; 40:1019-23.

18. Margalith I, Gillon G, Gordon D. Urinary incontinence in women under 65: quality of life, stress related to incontinence and patterns of seeking health care. Qual Life Res 2004;13:1381-90.

19. Huang AJ, Brown JS, Kanaya AM, Creasman JM, Ragins AI, Van Den Eeden SK, et al. Quality-of-life impact and treatment of urinary incontinence in ethnically diverse older women. Arch Intern Med 2006;166:2000-6.

20. Monz B, Chartier-Kastler E, Hampel C, Samsioe G, Hunskaar S, Espuna-Pons $\mathrm{M}$, et al. Patient characteristics associated with quality of life in European women seeking treatment for urinary incontinence: results from PURE. Eur Urol 2007;51:1073-81.

21. Ozerdogan N, Beji NK, Yalçin O. Urinary incontinence: its preva- lence, risk factors and effects on the quality of life of women living in a region of Turkey. Gynecol Obstet Invest 2004;58:145-50.

22. Kocaoz S, Talas MS, Atabekoglu CS. Urinary incontinence in pregnant women and their quality of life. J Clin Nurs 2010;19:3314-23.

23. Tozun M, Ayranci U, Unsal A. Prevalence of urinary incontinence among women and its impact on quality of life in a semirural area of Western Turkey. Gynecol Obstet Invest 2009;67:241-9.

24. Hsieh CH, Lee MS, Lee MC, Kuo TC, Hsu CS, Chang ST. Risk factors for urinary incontinence in Taiwanese women aged 20-59 years. Taiwan J Obstet Gynecol 2008;47:197-202.

25. Masue T, Wada K, Nagata C, Deguchi T, Hayashi M, Takeda N, et al. Lifestyle and health factors associated with stress urinary incontinence in Japanese women. Maturitas 2010;66:305-9.

26. Vinker S, Kaplan B, Nakar S, Samuels G, Shapira G, Kitai E. Urinary incontinence in women: prevalence, characteristics and effect on quality of life: a primary care clinic study. Isr Med Assoc J 2001; 3:663-6. 